Review

\title{
Neurobehavioral Alterations in Occupational Noise Exposure: A Systematic Review
}

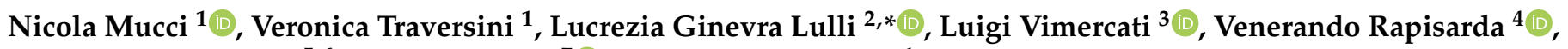 \\ Raymond Paul Galea ${ }^{5,6}$, Simone De Sio ${ }^{70}$ and Giulio Arcangeli ${ }^{1}$ \\ 1 Department of Experimental and Clinical Medicine, University of Florence, 50139 Florence, Italy; \\ nicola.mucci@unifi.it (N.M.); veronica.traversini@unifi.it (V.T.); giulio.arcangeli@unifi.it (G.A.) \\ 2 Occupational Medicine School, University of Florence, 50139 Florence, Italy \\ 3 Department of Interdisciplinary Medicine, Occupational Health Division, University of Bari, 70121 Bari, Italy; \\ luigi.vimercati@uniba.it \\ 4 Department of Clinical and Experimental Medicine, University of Catania, 95131 Catania, Italy; \\ vrapisarda@unict.it \\ 5 Faculty of Medicine and Surgery, University of Malta, MSD 2080 L-Imsida, Malta; raymond.galea@um.edu.mt \\ 6 Malta Postgraduate Medical Training Programme, Mater Dei Hospital, MSD 2090 L-Imsida, Malta \\ 7 Department of Anatomical, Histological, Forensic and Locomotor Apparatus Sciences, \\ Sapienza University of Rome, 5 Piazzale Aldo Moro, 00185 Rome, Italy; simone.desio@uniroma1.it \\ * Correspondence: lucreziaginevra.lulli@unifi.it
}

Citation: Mucci, N.; Traversini, V.; Lulli, L.G.; Vimercati, L.; Rapisarda, V.; Galea, R.P.; De Sio, S.; Arcangeli, G. Neurobehavioral Alterations in Occupational Noise Exposure: A Systematic Review. Sustainability 2021, 13, 12224. https://doi.org/ $10.3390 /$ su132112224

Received: 9 September 2021

Accepted: 22 October 2021

Published: 5 November 2021

Publisher's Note: MDPI stays neutral with regard to jurisdictional claims in published maps and institutional affiliations.

Copyright: (c) 2021 by the authors. Licensee MDPI, Basel, Switzerland. This article is an open access article distributed under the terms and conditions of the Creative Commons Attribution (CC BY) license (https:// creativecommons.org/licenses/by/ $4.0 /)$.

\begin{abstract}
The psychology of sustainability and sustainable development emphasizes the value to ensure health and well-being in different environments, including workplaces. Chronic exposure to noise can cause several extraordinary effects and involve all the systems of the human organism. In addition to cardiovascular, gastrointestinal, and immune effects, the data in the literature show alterations in behavioral disturbances, memory capacity, and cognitive performance. Through this systematic review, the authors try to find out the main neurobehavioral alterations in the case of occupational exposure to noise. The literature review included articles published in the major databases (PubMed, Cochrane Library, Scopus, Embase), using a combination of some relevant keywords. This online search yielded 4434 references; after selection, the authors analyzed 41 articles (4 narrative reviews and 37 original articles). From this analysis, it appears that the main symptoms are related to psychological distress, annoyance, sleep disturbances, and cognitive performance. Regarding tasks, the most frequent employments concern school staff, followed by employees from various industrial sectors and office workers. Although the causes are still widely debated, it is essential to protect these workers against chronic exposure to noise. In fact, in addition to a hearing loss, they can manifest many other related discomforts over time and compromise their full working capacity, as well as expose them to a greater risk of accidents or absences from work.
\end{abstract}

Keywords: occupational noise; job; work; behavioral disorders; psychological disorders; annoyance; occupational medicine; prevention

\section{Introduction}

The psychology of sustainability and sustainable development [1-3] is focused on health and well-being of individual/s in different environments. A healthy workplace, through sustainable culture, climate, and practices, create an environment that protects and boosts workers health and safety, as well as organizational effectiveness. Sustainable development can be considered a primary prevention that fosters well-being of the individual and the society. Considering this framework and the need for the development of sustainable workplaces, this systematic review aims to examine the main neurobehavioral alterations in case of occupational exposure to noise. Environmental exposure to high noise levels has been associated with mental health [4,5]. In fact, anxiety, emotional stress, nausea, headache, instability, sexual impotence, mood swings, increased social conflicts or general 
psychiatric disorders such as neurosis, psychosis, and hysteria are frequent symptoms linked to important exposures to noise [6]. Furthermore, high levels of environmental noise can interfere with the central, peripheral, and autonomic nervous systems such as, for example, alarm reflex and orientation reaction, modifications of the EEG trace, increase in intracranial pressure, headache, and reduction of chronaxia [7].

From this evidence, it can be hypothesized that the extra-auditory effects of noise occur through a series of nervous circuits which, through the autonomic nervous system, act on the cardiovascular, gastrointestinal, endocrine, central nervous and immune system. These anatomical connections of the auditory pathways with the reticular formation may explain the effects of noise on the level of behavioral activation (arousal), pain, and sleep [8]. Besides, some neurobehavioral manifestations may be the consequence of changes in chemical transmissions.

For example, annoyance and sleep disorders are some of the most widespread and documented responses to chronic noise exposure [9-12]. Annoyance reactions are proportional to the degree of interference of noise in daily activities, but also to coping strategies, that is, to the ability of the subject exposed to noise to adaptively modify his or her own behavior in response to the auditory stimulus [13].

However, the hypotheses on the relationship between these phenomena and exposure to noise are controversial and widely debated. Through several major studies conducted to define the interactions between noise, annoyance, and mental disorders, Stansfeld concluded that ambient noise does not cause clinically defined psychiatric disorders [14]. Speedwell and Caerphilly also came to the same conclusion [15]. However, from the longitudinal results of the Caerphilly study, there is a weak and non-linear association between noise exposure and increased anxiety [6,16].

Nevertheless, it is necessary to consider how the extent and duration of the effects are determined in part by other variables, such as individual sensitivity, lifestyle, and environmental conditions $[17,18]$.

Regarding jobs, the data in the literature show that occupational exposure to high and prolonged industrial noise can lead to alterations in psychomotor tests, decreased reaction times to acoustic and visual stimuli [19], cognitive deficits, especially affecting the memory function [20-22], and alterations in attentional capacity [12,21,23,24]. Moreover, other characteristics of noise, such as frequency, duration of exposure, and interruptions in the exposure can be relevant for the effects of the noise on human well-being. For example, irregular or pulsating noises can be more annoying than a steady noise: intensity alone is not an adequate parameter to describe noise exposure, especially when it comes to neurobehavioral effects. In addition, noise exposure can cause neurobehavioral effects indirectly-for example, causing distraction or difficulties in interactions between people. The purpose of this systematic review is to explore the interferences of noise on human neurobehavior. In particular, it aims to define what neurobehavioral alterations can occur in workers exposed to occupational/workplace noise and possible association and risk factors. Since a literature review exploring the extra-auditory effects of the exposure to occupational noise was conducted in 2011 [25], this review aims to collect scientific evidence of the last 10 years. Restricting the search to the last 10 years will reduce the heterogeneity of studies and the possible bias, considering the technical and legislative progress made to reduce occupational noise in the last decade [26].

\section{Materials and Methods}

This systematic review follows the Prisma Statement [27].

\subsection{Literature Research}

The research included articles published in the last 10 years, from 2010 to 15 September 2020, on the major online databases (PubMed, Cochrane Library, Scopus, Embase, Google Scholar). The search strategy used a combination of controlled vocabulary and free text terms based on the following keywords: work, job, task, workplace, noise, loud, 
sound, occupational, environment, neurobehavioral, psychological, mental, neural. All research fields were considered. The search string used was the following: $(((($ noise $)$ OR (sound)) OR (sound level)) OR (loud)) AND ((((((((workplace) OR (work)) OR (job)) OR (job task)) OR (occupation)) OR (occupational)) OR (environmental)) OR (environment))) AND ((((((neurobehavioral) OR (behavioral)) OR (behavioral)) OR (neurobehavioral)) OR (psychological)) OR (mental)) OR (neural)).

In particular, we conducted a research strategy in the databases on the effects of noise exposure on workers' health by applying the PICO statement. The population studied was that of workers, with no difference in age, gender, or type of job. The type of intervention concerned any type of noise exposure in the workplace. The health outcomes considered were those related to neurobehavioral changes second the most recent studies. We included short-term effects and medium- to long-term effects, such as insomnia, sleep, fatigue, impaired concentration and memory, changes in work performance, errors, mood changes with irritability, anxiety, aggression, depression, annoyance. If found, physiological measures and work-life balance, such as hormone excretion level or changes in management of social and family life, were included.

The pre-specified search terms of PICO are focused upon in Table 1.

Table 1. PICO statement.

\begin{tabular}{lr}
\hline Population & $\left(\left(\right.\right.$ workplace) OR (work $\left.\left.{ }^{*}\right)\right)$ OR (job)) OR (job task)) OR (occupation)) OR (occupational)) OR (environmental)) OR (environment) \\
\hline Interventions & $($ (noise) OR (sound)) OR (sound level) OR (loud) \\
\hline Comparison & N.A. \\
\hline Outcomes & ((neurobehavioral) OR (behavioral)) OR (behavioral)) OR (neurobehavioral)) OR (psychological)) OR (mental)) OR (neural)) \\
\hline
\end{tabular}

Additionally, we practiced a manual search on reference lists of the selected articles and reviews to carry out a wider analysis. Two independent reviewers read titles and abstracts of the reports identified by the search strategy. They selected relevant reports according to inclusion and exclusion criteria. Doubts or disagreements were solved by discussion with a third researcher.

Subsequently, they independently screened the corresponding full text to decide on final eligibility. Finally, the authors eliminated duplicate studies and articles without full texts.

Data were mainly obtained from the published results but also from any other supplementary sources when these were available. In particular, the authors selected date and country of publication, sample size, involved noise source, exposure decibel, and kind of reported disorders. In addition, the authors highlighted the number of studies included for all reviews and the length of the study in the case of experiment or cohort studies.

\subsection{Quality Assessment}

Three different reviewers assessed the methodological quality of the selected studies with specific rating tools, to reduce the risk of introducing any bias. We used the INSA method "International Narrative Systematic Assessment" to judge the quality of narrative reviews [28], AMSTAR to evaluate systematic reviews, and the Newcastle Ottawa Scale to evaluate cross-sectional, cohort studies, and case control studies $[29,30]$, while we applied the Jadad scale for randomized clinical trials [31]. In addition, to reduce the risk of bias, we used RobVis (BARR, Bristol, UK), a specific tool for systematic reviews [32] (see Appendix A Figures A1 and A2).

\subsection{Eligibility and Inclusion Criteria}

As stated by the PICO scheme above, the studies included in this review focus on occupational noise and professional categories exposed to this risk. Studies considering workers exposed to environmental noise in the workplace are also included. The studies included refer to occupational noise, measured through quantitative and qualitative assess- 
ment. We included studies on principal neurobehavioral consequences to this exposure, in particular annoyance, sleep disorders, short memory, poor concentrations, and working performance. All types of study designs were included. No restrictions were applied for language or country.

\subsection{Exclusion Criteria}

We excluded reports related only to environmental exposure or noise pollution, not specifically conducted in a workplace setting, publications on programmatic interventions, and studies not considering diseases or disturbances linked to noises. We restricted our search to the last 10 years, as explained in the Introduction. We also excluded reports of less academic significance, editorial articles, individual contributions, and purely descriptive studies published in scientific conferences, without any quantitative and qualitative inferences.

\section{Results}

The online search yielded 4485 studies: PubMed (3056), Scopus (21), Cochrane Library (13), Embase (115), Google Scholar (1280). Of these, 4434 studies were excluded because they were deemed unrelated to noise-related problems. Among the remaining studies, four articles were also excluded because they were duplicates. Duplicate publications were carefully eliminated in order not to introduce bias, by comparing the names of the authors, the topics addressed, the workers examined, and the results obtained. Another six publications were deleted because the full text was not available. In conclusion, 41 studies were finally included in this analysis (Figure 1). Of these, 4 are literature reviews (2 systematic; 2 narrative) and 37 are original articles. Among the latter, 16 are cross-sectional studies, 2 cohort studies, 5 case control studies, 2 pilot studies, 1 observational study, 10 experimental studies, and 1 mixed (cross / experimental) study (Table 2).

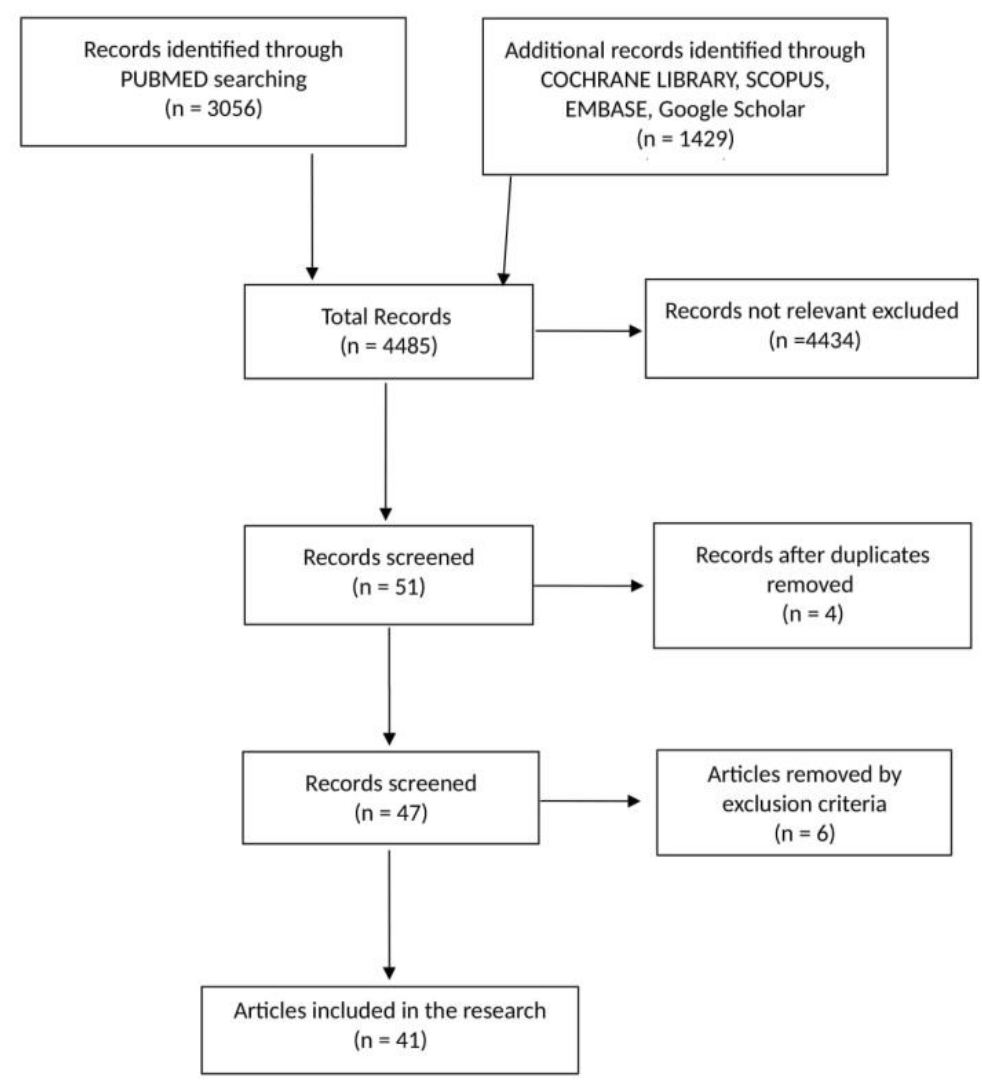

Figure 1. Flowchart of bibliographic research. 
Table 2. Studies including in this systematic review, in alphabetical order.

\begin{tabular}{|c|c|c|c|c|c|}
\hline First Author & Year & Country & Study & Categories Workers & Diseases \\
\hline Abbasi & 2015 & Iran & pilot study & wind farmers & general health, sleep disorders, annoyance \\
\hline Alimohammadi & 2019 & Iran & case control & automotive workers & cognitive performance, annoyance \\
\hline Alimohammadi & 2018 & Iran & cross-sectional & automotive workers & aggressive behavior \\
\hline Alimohammadi & 2010 & Iran & cross-sectional & white collar employees & annoyance \\
\hline Azuma & 2017 & Japan & cross-sectional & office workers & psychological distress \\
\hline Burns & 2019 & USA & cross-sectional & electronic waste workers & perceived stress \\
\hline Cheng & 2019 & China & case control & military & working memory performance \\
\hline Clausen & 2013 & Denmark & cohort study & office workers & long-term sickness absence \\
\hline Deng & 2019 & China & cross-sectional & not specified & depression \\
\hline Di Blasio & 2019 & Italy & cross-sectional & office workers & annoyance, mental health, well-being \\
\hline $\begin{array}{l}\text { Eysel- } \\
\text { Gosepath }\end{array}$ & 2012 & Germany & cross-sectional & teachers & annoyance, sleep disorders, fatigue \\
\hline Fredriksson & 2015 & Sweden & cross-sectional & obstetrics & annoyance, work-related stress \\
\hline Fredriksson & 2019 & Sweden & cohort study & teachers & work-related stress \\
\hline Freiberg & 2018 & Germany & systematic review & wind industries & annoyance, sleep disorders \\
\hline Habibi & 2013 & Iran & experimental study & university personnel & speed of work, annoyance \\
\hline Horsten & 2018 & Netherland & systematic review & healthcare workers & sleep disorders \\
\hline Hua & 2014 & Sweden & case control & employees & cognitive skills \\
\hline $\begin{array}{l}\text { Irgens- } \\
\text { Hansen }\end{array}$ & 2015 & Norway & experimental study & navy personnel & cognitive performance \\
\hline Jahncke & 2011 & Sweden & experimental study & open-plan offices & cognitive performance \\
\hline Keller & 2017 & USA & experimental study & military & cognitive performance \\
\hline Keller & 2018 & Switzerland & observational study & healthcare workers & cognitive performance \\
\hline Kim & 2016 & Korea & cross-sectional & $\begin{array}{l}\text { office work, sales, } \\
\text { manufacturing }\end{array}$ & smoking intensity \\
\hline Kristiansen & 2014 & Denmark & cross-sectional & teachers & mental health, fatigue \\
\hline $\begin{array}{l}\text { Mahendra } \\
\text { Prashanth }\end{array}$ & 2011 & India & narrative review & industrial workers & sleep disorders, cognitive performance \\
\hline Mapuranga & 2020 & Zimbabwe & cross-sectional & manufacturing workers & job performance \\
\hline Milenovic & 2018 & Serbia & case control & $\begin{array}{l}\text { manual/administrative } \\
\text { workers }\end{array}$ & aggressiveness \\
\hline Molesworth & 2015 & Australia & experimental study & aircraft personnel & $\begin{array}{c}\text { recognition memory, working memory, } \\
\text { reaction time }\end{array}$ \\
\hline Monteiro & 2018 & Portugal & pilot study & students/fast food employees & working memory performance \\
\hline Nari & 2020 & Korea & cross-sectional & employees & sleep disorders \\
\hline Oenning & 2018 & Brazil & cross-sectional & $\begin{array}{l}\text { various (public, private, } \\
\text { domestic, farmworkers, } \\
\text { technicians, managers) }\end{array}$ & depressive disorders \\
\hline Onchang & 2018 & Thailand & case control & university personnel & annoyance \\
\hline Realyvásquez & 2016 & Spain & experimental study & manufacturing workers & $\begin{array}{c}\text { working } \\
\text { performance, job satisfaction, aggressivity }\end{array}$ \\
\hline Schlittmeier & 2013 & Germany & $\begin{array}{l}\text { cross/experimental } \\
\text { study }\end{array}$ & office workers & cognitive performance, annoyance \\
\hline Sjodin & 2012 & Sweden & cross-sectional & preschool personnel & work-related stress, sleep disorders \\
\hline Sloof & 2010 & Netherland & experimental study & university personnel & work motivation \\
\hline Smith & 2010 & UK & experimental study & university personnel & working memory performance \\
\hline Tomic & 2018 & Sweden & experimental study & not specified & working memory performance \\
\hline Wassermann & 2013 & USA & case control & university personnel & attention \\
\hline Wright & 2016 & UK & experimental study & university personnel & $\begin{array}{l}\text { cognitive performance, } \\
\text { psychological disorders }\end{array}$ \\
\hline Yoon & 2014 & Korea & cross-sectional & white, pink, blue collars & $\begin{array}{c}\text { depressive disorders, } \\
\text { suicidal ideation, annoyance }\end{array}$ \\
\hline Yuen & 2014 & Malaysia & narrative review & manufacturing workers & annoyance, sleep disorders \\
\hline
\end{tabular}


Sweden is the country where most of the studies were published $(6 / 41 ; 14.6 \%)$. Most of the articles were published in 2018 (9/41;21.9\%), followed by 2019 (6/41; 14.6\%).

We used the VosViewer tool to create a bibliographic map of the articles retrieved [33]. Figure 2 shows the keywords' co-occurrence network of the articles in the sample. Node sizes are proportional to how many articles are labeled with the keyword selected. Two nodes are connected if the respective keywords are co-associated in an article. The restriction to generate the network is that each keyword occurs almost three times; 36 terms were identified and the total strength of the co-occurrence links with other keywords were calculated. The term "human" was excluded from the network map because all the studies considered have humans as subjects. The network map shows three clusters of keywords' co-occurrence. The major disturbances linked to noise are "depression," "psychological stress," "hearing loss," which are associated with "occupational disease" and have a link to the keyword "middle aged." The cluster shows keywords such as "cross-sectional studies," "prevalence," and "risk factors," suggesting the type of prevalent studies in the selected articles. Moreover, "surveys and questionnaires" seems to be the most used tools in the investigations (cluster red on the right side). "Attention," "short-term memory," and "task performance" are the other keywords shown on the map and linked to "occupational noise" and "transportation noise" (cluster green on the left). Cluster blue on the top groups' keywords related to work environment makes a connection between ergonomics, noise, and work performance.

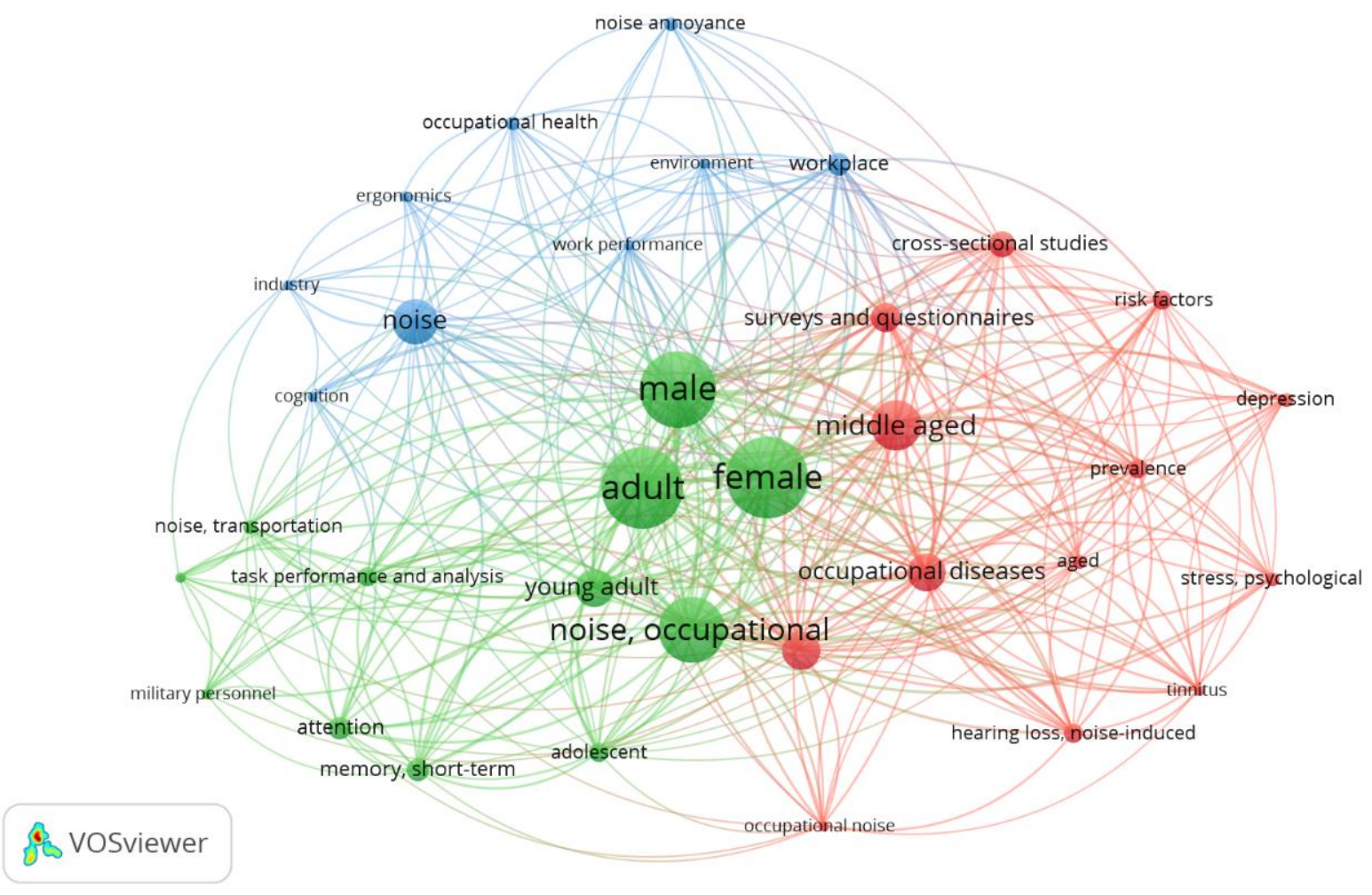

Figure 2. Network map of co-occurrence keywords.

Selected articles examine various symptoms related to psychological distress and reported by the samples, such as annoyance $(11 / 41 ; 26.8 \%)$, sleep disturbances $(9 / 41$; $21.9 \%)$, and reduced work/ cognitive performance (14/41;34.1\%). Taking into consideration the tasks examined, it was found that the most frequent analyses concern school staff $(10 / 41$; $24.3 \%)$, followed by employees from various industrial sectors $(9 / 41 ; 21.9 \%)$ and office workers $(6 / 41 ; 14.6 \%)$. 


\subsection{Narrative and Systematic Reviews}

Regarding the methodological quality of the systematic reviews, the AMSTAR scores show an average, a median, and a modal value of 9 , indicating the high quality of the studies (Table 3). Regarding narrative reviews scores, the INSA score shows an average and a median value of 5.5 , indicating an intermediate quality.

Table 3. Reviews included in this article, with their relative score.

\begin{tabular}{|c|c|c|c|}
\hline First Author & Included Articles & Results & Score \\
\hline Freiberg & 20 & $\begin{array}{l}\text { Exposure to onshore wind turbine noise leads to annoyance, sleep disorders, } \\
\text { and lowered general health. }\end{array}$ & A. 9 \\
\hline Horsten & 20 & $\begin{array}{c}\text { Effect of noise on sleep in the ICU seems to have a significant effect on the } \\
\text { arousals in six studies performed with healthy volunteers. The majority of the } \\
\text { observed arousals remain unexplained because they did not occur within } 3 \mathrm{~s} \\
\text { of a sound peak. }\end{array}$ & A. 9 \\
\hline Mahendra Prashanth & narrative & $\begin{array}{l}\text { The data suggest that significant adverse health effects due to industrial noise } \\
\text { include auditory and heart-related problems. The study provides strong } \\
\text { evidence for the claims that noise with a major frequency characteristic of } \\
\text { around } 4 \mathrm{kHz} \text { has auditory effects and being deficient in data fails to show } \\
\text { any influence of noise frequency components on non-auditory effects. }\end{array}$ & I.5 \\
\hline Yuen & narrative & $\begin{array}{l}\text { Results from the survey, monitoring, short-term, and longitudinal studies } \\
\text { have positioned the noise pollution scenario in Malaysia at a critical level. } \\
\text { This highlighted the resurgent need of practical solutions by the government, } \\
\text { non-governmental organizations, and educational institutions to generate a } \\
\text { healthy working and living environment. }\end{array}$ & I.6 \\
\hline
\end{tabular}

However, each of these reviews analyzed different work environments, with different complaints reported by workers.

For example, topics covered by Freiberg et al. [34] included some job duties involving wind turbines (manufacturing, transportation, installation, operation, and maintenance). The study population, however, was composed not only of workers in the wind industry, but also of others who worked around wind farms. The literature showed how the noise of wind turbines had a significant influence on the development of annoyance, daytime sleepiness, and general health problems among workers; moreover, even the workers in other sectors but within $3 \mathrm{~km}$ of the turbines show a certain prevalence of disorders attributable to this source of noise [35].

Horsten et al., on the other hand, analyzed the scientific evidence of the effect of noise in ICUs on sleep quality. They showed that such noise in the ICU has a significant negative effect, with increased arousals in six studies performed with healthy volunteers; however, there is a high risk of bias due to the multifactorial nature of sleep disorders in intensive care, the different protocols implemented by the different experiments, the sound levels not always measured, and finally the administration of questionnaires not always standardized with subjective symptoms [35].

Mahendra's review focuses on studies published between 1988 and 2009 on the effects of industrial noise, analyzing auditory and non-auditory effects. Some of his included studies have shown that with lasting exposures between 43 and $73 \mathrm{~Hz}$, particular disturbances can occur, such as lack of visual acuity, a drop in IQ scores, distortion of spatial orientation, poor muscle coordination, loss of balance, and confused speech. However, specific noise levels in terms of frequencies that predict health impacts have not yet been validated [25].

Finally, in the case of exposure to vehicular traffic, Yuen highlighted how the discomfort associated with continuous exposure to traffic noise can create an unpleasant condition in highway toll workers and residential communities in the surrounding areas. Traffic noise levels are typically between 75 and $85 \mathrm{dBA}$ and occasionally reach $90 \mathrm{dBA}$. Respondents wake up more often, have had poorer sleep quality, and feel sleepy during their day work. In addition, they negatively assessed the installation of the so-called TRS "crossroad strips," 
as they generate excessive vibrations and pulsating or impulsive noises, similar to the sound of hammers, firecrackers, or small explosions [36].

\subsection{Original Articles}

The scores assigned to the original articles have an average value of 5.16 , a mode of 7 , and a median of 6; this indicates an intermediate quality of the studies (Tables 4 and 5).

Researchers from Iran, China, Japan, Sweden, Korea, Denmark, Serbia, Brazil, Thailand, Zimbabwe, and USA have obtained the highest values (NEW CASTLE Scale = 7). Sweden remains the country where the most articles related to the topic have been published in the last 10 years $(6 / 37 ; 16.2 \%)$, followed by Iran $(5 / 37 ; 13.5 \%)$.

To carry out the results and considering the quantity of the selected articles, we proceed with a synthesis of the results based on the main disorders and workers' categories found by the authors.

\subsubsection{Main Disorders}

The main disorders analyzed include cognitive performance, attention, and motivation in the workplace $(15 / 37 ; 40.5 \%)$, followed by annoyance $(4 / 37 ; 10.8 \%)$, stress $(3 / 37 ; 8.1 \%)$, mood changes with depression and/or aggression $(2 / 37 ; 5.4 \%)$, sleep disturbances $(1 / 37$; $2.7 \%$ ). Finally, six articles $(6 / 37 ; 16.2 \%$ ) analyze multiple disorders (for example, depression and annoyance, stress and sleep, stress and annoyance, sleep and annoyance, and cognitive performance and annoyance).

As for the questionnaire administered to workers, some authors investigate aspects concerning general health, through questionnaires such as General Health Questionnaire (GHQ) and Patient Health Questionnaire (PHQ), or work-related stress, through effortreward imbalance (ERI), Perceived Stress Scale (PSS), and Copenhagen Psychosocial Questionnaire (COPSOQ). Other studies evaluate work performance more specifically, for example, through the Stroop test (ST), reaction time (RT), memory test, and the sustained attention to response test (SART).

Regarding cognitive functions or various logic and memory skills, most authors agree that their quality decreases with exposure to noisy sources. For example, Alimohammadi proved that all the cognitive indicators have a significant relationship with exposure to noise, but in all the cognitive indicators annoyance does not have a significant relationship with cognitive performance [37]. In the study by Monteiro et al., people tested for memory, attention, and serial recall tended to make more mistakes as the noise intensity increased. The participants experienced growing discomfort, stress, and annoyance as the sound pressure levels increased $(p<0.05)$ [38]. Better cognitive performance can be related to higher education and younger age [39].

For Cheng, the effects of noise can be traced with magnetic resonance imaging. Exposure group scored worse on mental tests, and they had less brain gray matter volumes in the left hippocampus, right middle frontal gyrus, and right inferior parietal lobule compared with the control group $(p<0.002, p<0.05)$. The same group showed significantly lower regional homogeneity values in the left amygdala, left hippocampus, left thalamus, and right middle/superior frontal gyrus $(p<0.01)$ [40].

However, other authors have found conflicting information; for example, Wassermann found that the participants' reaction times are slower in the control condition than in the pink and TV sitcom noise conditions. So, complex television noise does not impair attention, while pink noise, or a signal that combines relevant frequencies, does [41]. For Keller, speech intelligibility has a relevant role in communication; in fact, as the speech intelligibility goes down, missed communication rate and requests for repeat backs increase $(p<0.001)$. Communication errors in some tests were significant in relation to the decrease in speech intelligibility. However, overall eye behaviors were not overly impacted by the different speech intelligibility levels (eye blink rates, pupil dilation, and basic measures of saccade and fixation metrics showed no difference with increased fatigue, strain, and noise levels) [42]. 
Table 4. Cross articles included in this review, in alphabetical order, with their relative score.

\begin{tabular}{|c|c|c|c|c|c|}
\hline First Author & Included Subjects & Exposure's Range & Questionnaire/Tests & Results & Score \\
\hline Alimohammadi & 250 & $70-90 \mathrm{~dB}$ & Buss and Perry's questionnaire & $\begin{array}{l}\text { There was a significant }(p<0.05) \text { correlation between the measured noise } \\
\text { intensity and the aggression level. }\end{array}$ & N.7 \\
\hline Alimohammadi & 495 & LEPd 65.05 & WNSS, SAS, EPI, AQ, BDI & $\begin{array}{l}\text { Noise annoyance among people who reported their workplace as high in } \\
\text { ambient noise is } 4.05 \text { times more than that among other people. }\end{array}$ & N.7 \\
\hline Azuma & 489 & not specified & MM40, JSQ & $\begin{array}{c}\text { Carpeting, unpleasant chemical odors, noise, dust, and dirt were } \\
\text { significant risk factors for BRSs. }\end{array}$ & N.7 \\
\hline Burns & 46 & $78.8 \pm 5.9 \mathrm{dBA}$ & PSS & $\begin{array}{l}\text { Perceived stress level and perceived noise exposure were associated with a } \\
\text { significantly greater number of injuries. }\end{array}$ & N.6 \\
\hline Deng & 106 & not specified & ZSDS, PSQI & $\begin{array}{l}\text { Higher depressive status was positively correlated with THI score, PSQI } \\
\text { score, and duration of occupational NIHL. }\end{array}$ & N.6 \\
\hline Di Blasio & 1078 & not specified & not validated & $\begin{array}{l}\text { Irrelevant speech increases noise annoyance, decreases work performance, } \\
\text { and increases symptoms related to mental health and well-being more in } \\
\text { open-plan than in shared offices. }\end{array}$ & N.6 \\
\hline Eysel-Gosepath & 43 & $65-87 \mathrm{~dB}$ & not validated & $\begin{array}{l}\text { Teachers experience the highest sound levels in the schoolyard, corridors, } \\
\text { and classrooms, and } 68 \% \text { of the teachers are annoyed by the noise. }\end{array}$ & N.5 \\
\hline Fredriksson & 115 & 56-87 dB Laeq & ISO/TS 15,666 & $\begin{array}{l}\text { Work-related stress and noise annoyance at work were reported by almost } \\
\text { half of the personnel. Sound-induced auditory fatigue was associated with } \\
\text { work-related stress and noise annoyance at work. }\end{array}$ & N.7 \\
\hline Kim & 3769 & not specified & KNHANES VI-3 & $\begin{array}{l}\text { Dirty workplace and exposure to occupational noise are significant factors } \\
\text { increasing the smoking intensity for manufacturers. }\end{array}$ & N.7 \\
\hline Mapuranga & 250 & not specified & not validated & $\begin{array}{l}\text { Occupational noise had a positive and significant effect on attitudes } \\
\text { towards occupational exposure and perceived susceptibility to hearing } \\
\text { loss among manufacturing workers. }\end{array}$ & N.7 \\
\hline Nari & 30,837 & not specified & KWCS & $\begin{array}{l}\text { OR of insomnia due to noise exposure was } 1.10 \text { and } 1.07 \text { in men and } \\
\text { women, respectively. For noise plus vibration exposure, OR was } 1.83 \text { in } \\
\text { men and } 3.14 \text { in female workers. }\end{array}$ & N.7 \\
\hline Oenning & 60,202 & not specified & PHQ9 & $\begin{array}{c}\text { Associations of chemical substances and noise with MDD were found to } \\
\text { be significant among women only (the two interaction terms were } \\
\text { significant at } p<0.05) \text {. }\end{array}$ & N.7 \\
\hline Schlittmeier & 74 & $35-55 \mathrm{~dB}$ & not validated & $\begin{array}{l}\text { Background speech is subjectively perceived as a severe problem, and the } \\
\text { different noise abatement measures affect objective performance and } \\
\text { subjective ratings differently. }\end{array}$ & N.7 \\
\hline Sjodin & 101 & 71 Laeq mean & SOFI, ERI, KSS, SMBQ & $\begin{array}{l}\text { Stress and energy output were pronounced among the employees, and } \\
\text { about 30\% of the staff experienced strong burnout syndromes. }\end{array}$ & N.7 \\
\hline Yoon & 10,020 & not specified & not validated & $\begin{array}{l}\text { Compared to the no noise annoyance group, ORs of the severe annoyance } \\
\text { groups were } 1.58 \text { and } 1.76 \text { in men and } 1.49 \text { and } 1.41 \text { in women for } \\
\text { depressive symptoms and suicidal ideation, respectively. }\end{array}$ & N.7 \\
\hline
\end{tabular}


Table 5. Cohort/case control/pilot/observational studies in alphabetical orders, with relative scores.

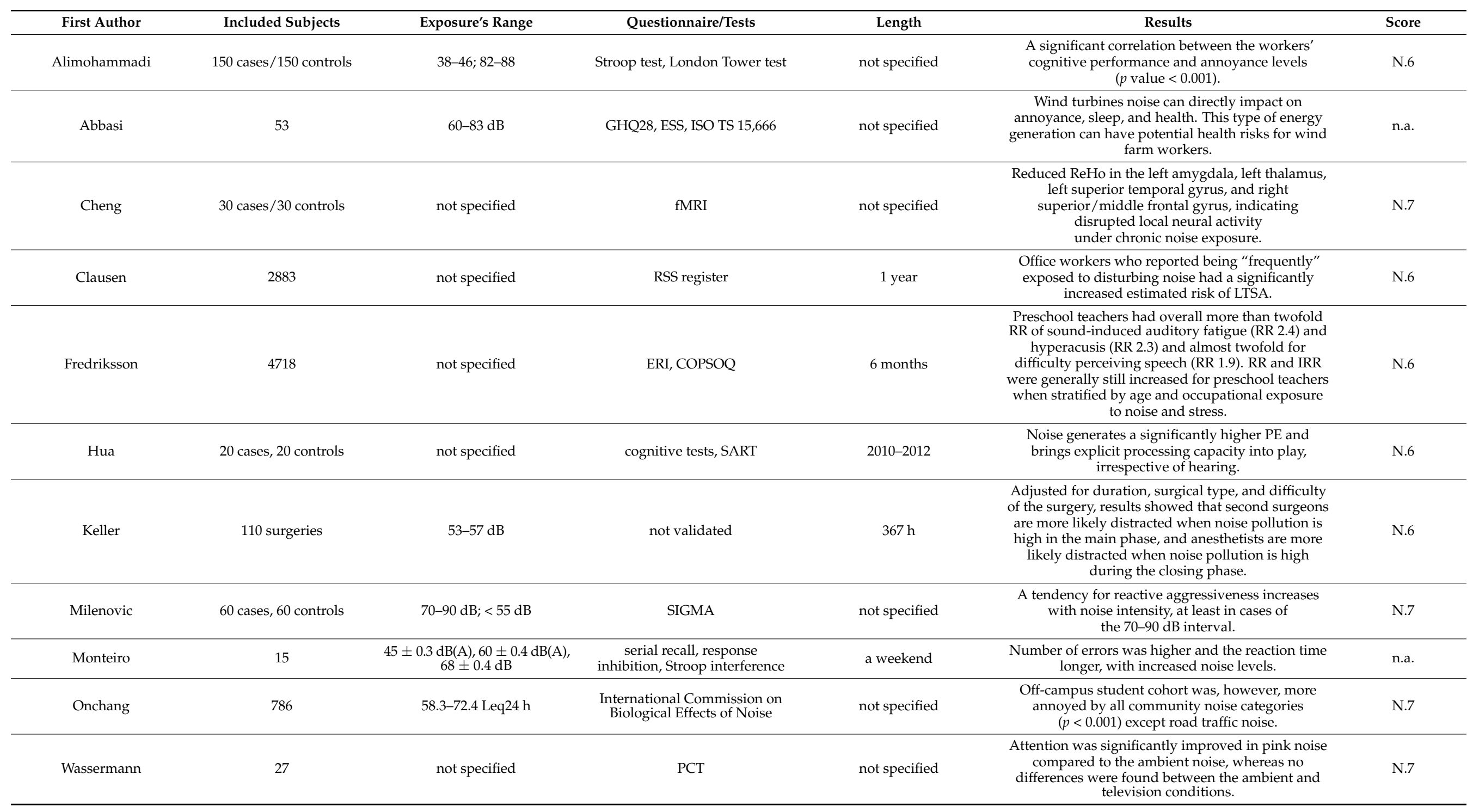


Another disorder frequently found in the selected articles is annoyance. Some authors have looked for a correlation between this reported symptom and some individual or work-related factors. For example, Yoon found a difference between gender (ORs 1.58 for men, 1.49 for women with depression, and 1.41 for women with suicidal ideation) and sleep time (ORs 2.95 for workers with less than five hours of sleep) [43].

Moreover, the workplace is important. In fact, Di Biasio showed that workers in shared offices are less annoyed than those who work in open-plan offices. In this last group, he observed a difference between gender (women are more annoyed), year range (51-65+ are more annoyed), and type of workplace (those who work in sales or public affairs sectors or engineering and teaching sectors are more annoyed) [44]. Additionally, a very noisy environment can lead to hearing fatigue and tinnitus, which in turn are related to work-related stress and annoyance [45].

Finally, annoyance is related to individual sensitivity. In fact, for Alihommadi, noise annoyance is significantly related to noise sensitivity $(p=0.0015)$. People with higher level of noise sensitivity were more annoyed than those with moderate $(O R=11.78)$ and low sensitivity $(\mathrm{OR}=4.88)$. Moreover, medium level of anxiety seemed to worsen noise annoyance, while in individuals with either low or high level of anxiety, noise annoyance was lower $(p=0.005)$ [46].

We found many other types of neurobehavioral disorders with noise exposure. For example, Azuma found three more frequent general symptoms, such as "tension, irritability, or nervousness," "feeling depressed," and "unusual tiredness, fatigue, or drowsiness" [47]. Besides, in Sjodin's study, preschool personnel described their occupational fatigue at midday in terms of lack of energy and motivation, physical discomfort, and sleepiness at work. These employees reported being more tired before going to sleep $(p<0.05)$. Higher levels of depression were related to higher sound fluctuation as perceived subjectively $(p<0.05)$ and the assessed morning cortisol correlated positively with noise annoyance during work $(\mathrm{r}=0.284, p<0.05)[48]$.

Mood swings were also found in the Oenning's and Deng's study; in fact, they found an association between chemical substances and noise with depressive symptoms among women belonging to various work categories $(p<0.05)$. Sometimes, depressive symptoms are secondary to hearing loss caused by exposure to noise and subsequent isolation $[49,50]$.

Insomnia is another ailment reported by workers. In his study, Nari found an increased risk of developing this discomfort in both genders, especially if exposed to vibrations at the same time (1.83/ CI 1.61-2.07 in men and 3.14/ CI 2.76-3.57 in women) [51]. Sleep disturbances appear to be triggered by annoyance, which in turn is related to noise exposure, but they do not appear to be related to the age of workers [52].

Another interesting fact is the finding of a greater tendency to develop aggression when exposed to noisy sources. In his study, Alihommadi found that it is present a positive correlation between the daily dose of noise received by the workers and aggressive behavior in terms of verbal and physical aggression, hostility, and anger $(p<0.05)$ [53]. Furthermore, Milenovic showed that a tendency for reactive aggressiveness increases with noise intensity, in particular between 70 and $90 \mathrm{~dB}(p<0.01)$; he also noted that length of employment did not affect levels of aggressiveness [54]. These conditions can cause workers to show a greater predisposition to addiction. For example, Kim discovered increased intensity of cigarette smoking in noisy and safety-threatening workplace environments [55]. Finally, a higher rate of occupational injuries has been related to greater perceived noise exposure in electronic waste recycling workers of low-income countries [56].

\subsubsection{Type of Workers}

School staff is the main categories of workers analyzed in original articles $(11 / 37$; $29.7 \%$ ), following by various employees (industry, farmers, manufacturing, etc.) and officeadministrative workers $(7 / 37 ; 18.9 \%)$, military personnel $(4 / 37 ; 10.8 \%)$, healthcare workers $(2 / 37 ; 5.40 \%)$. 
Among school staff, the variable factors that can correlate with a greater manifestation of neurobehavioral disorders are working age, hours of lessons, and workload. For example, in Eysel's study, sleep disturbances in teachers older than 45 years of age were common; tiredness and exhaustion in the evening, after a full day of work, was present in almost all the employees $(90 \%)$. In this context, $51 \%$ of the whole sample consider work as a physical and mental strain; older teachers report a significant worsening in these affectations with increasing years of professional activity in $81 \%$ of the cases [57]. Furthermore, in Fredriksson's study, symptoms generally occurred more often in older people $(p<0.05)$, excepting for hyperacusis and sound-induced auditory fatigue. The prevalence of such disorders increases significantly in people exposed to both noise and stressful working conditions compared to those unexposed $(p<0.05)$ [58].

The duration of exposure may influence the association between noise and symptoms. In Kristiansen's study, cognitive tests exhibited little changes when teachers with less than four lessons were excluded from the analyses. Moreover, the teachers' average noise exposure was moderately correlated with changes in TBT (two back test) performance, in particular when the analysis was limited to general classrooms (Spearman's rho $=-0.35$, $p=0.11$ ); instead, the scores in the sustained attention to response test (SART) did not correlate significantly with noise exposure or vocal load [59].

Finally, remaining in the school environment, even students can report related symptoms. Onchang found a difference between two students' cohorts, "the off-campus" (OG) and "inside-campus" (IG); the first suffered more than the others from all community noise categories (traffic, construction, recreation, and advertising; $p<0.001$ ). The largest differences between the two groups in the perception of noise annoyance were consistently found for telephone and personal communication for all the types of community noise; conversely, the smallest differences were for listening to radio and television, reading, and mental tasks. In the group of OG students, reading and mental tasks significantly influenced cumulative grade point average $(\mathrm{OR}=2.801, p<0.05)$ [60].

\subsection{Experimental Studies}

We found 10 experimental studies (10/37; 27\%). Iran, Norway, USA, Spain, Netherland, Sweden have obtained the highest value (Jadad scale $=3$ ) (Table 6). Below are some peculiarities found in this analysis.

In his experimental study, Irgens-Hansen evaluated cognitive performance under exposure to various noise levels among personnel working on board ships in the Royal Norwegian Navy. Reaction times were significantly higher in personnel exposed to values greater than $85.2 \mathrm{~dB}(\mathrm{~A})$ and in the exposed group in the range of 77.1-85.2 $\mathrm{dB}(\mathrm{A})$, compared to personnel exposed to values below $72.6 \mathrm{~dB}(\mathrm{~A})$. Furthermore, the latter reported a lower workload. Caffeine consumption and nicotine use did not differ significantly between the noise exposure groups [61].

The Molesworth study explored the effect on memory and psychomotor performance in being exposed to 75dBA broadband noise (simulation of an airplane cabin noise). When the performance of reaction times in the presence of noise was compared with conditions in which the volunteers had consumed alcohol, it was found that the impact of alcohol on reaction time was more severe than the noise itself [62].

Jahncke designed an experiment with the exposure of the 47 subjects tested in four different conditions (projecting films on nature, listening to the sounds of nature, with silence and with high/low noise). By testing memory capacity, participants scored lower when exposed to higher noise. Furthermore, the analysis revealed a significant interaction between noise and fatigue/lack of motivation: participants who viewed the film reported more energy than participants exposed to noise only $(p<0.01)$ and those who listened to the sounds of the nature $(p<0.05)$. Participants exposed to noise during the rest period ranked as less motivated (i.e., more disinterested) than participants who listened to the sounds of the river $(p<0.05)$ or watched the film $(p<0.01)$ [63]. 
In Smith's study, too, the beneficial role of music is highlighted. In fact, when participants are exposed to office noise, they exhibit lower performance alterations, although after a $10 \mathrm{~min}$ habituation period, their performance tends to improve. In the second part of the experiment, the author showed how instead an exposure to Mozart's works improved subsequent performances, especially as regards the visual-spatial reasoning activities [64].

Table 6. Experimental studies included in this review, with their relative score.

\begin{tabular}{|c|c|c|c|c|c|}
\hline First Author & Subjects & Exposure & Length & Results & Score \\
\hline Habibi & 96 & $65,85,95 \mathrm{~dB}$ & $0,20,40 \mathrm{~min}$ & $\begin{array}{l}\text { Increasing sound pressure level from } 65 \text { to } 95 \mathrm{~dB} \text { in } \\
\text { network " } \mathrm{A} \text { " increased the speed of work }(p<0.05) \text {. } \\
\text { Male participants got annoyed from the noise more } \\
\text { than females. Moreover, increase in sound } \\
\text { pressure level increased the rate of error }(p<0.05) \text {. }\end{array}$ & 3 \\
\hline Irgens-Hansen & 87 & $\begin{array}{l}<72.6 \mathrm{~dB}(\mathrm{~A}) \\
72.6-77.0 \mathrm{~dB}(\mathrm{~A}) \\
77.1-85.2 \mathrm{~dB}(\mathrm{~A}) \\
>85.2 \mathrm{~dB}(\mathrm{~A})\end{array}$ & 14 months & $\begin{array}{c}\text { Response time was significantly increased among } \\
\text { personnel exposed to }>85.2 \mathrm{~dB}(\mathrm{~A}) \text { and } 77.1-85.2 \\
\mathrm{~dB}(\mathrm{~A}) \text { compared to personnel exposed to } \\
<72.6 \mathrm{~dB}(\mathrm{~A}) \text {. }\end{array}$ & 3 \\
\hline
\end{tabular}

Participants remembered fewer words, rated themselves as more tired, and were less motivated with work in noise compared to low noise; those who saw a nature movie (including river sounds) rated themselves as having more energy after the restoration period in comparison with both the participants who listened to noise and river sounds.

Jahncke $\quad 47 \quad 39-51 \mathrm{~dB} \quad$ some hours Remaining in office noise during the restoration phase also affected motivation more negatively than listening to river sounds or watching the nature movie.

\begin{tabular}{|c|c|c|c|c|c|}
\hline Keller & 36 & $75 \mathrm{~dB}$ & some hours & $\begin{array}{l}\text { Noise (and its effect on speech intelligibility) can } \\
\text { have a significant negative impact on how well } \\
\text { sailors are able to communicate, especially in a } \\
\text { dynamic and high-stress environment. }\end{array}$ & 3 \\
\hline Molesworth & 32 & $75 \mathrm{~dB}$ & some hours & $\begin{array}{l}\text { Participants completed three different tests } \\
\text { (recognition memory, working memory, and } \\
\text { reaction time) in the presence of noise, with or } \\
\text { without noise attenuation headphones, and } \\
\text { without noise but with a BAC of } 0.05 \text { or } 0.10 \text {. } \\
\text { Simulated aircraft noise was found to affect } \\
\text { recognition memory but } \\
\text { not working memory or reaction time. }\end{array}$ & 2 \\
\hline Realyvásquez & 158 & not specified & not specified & $\begin{array}{l}\text { Noise and lighting have no direct effects on } \\
\text { employees' performance, but they do have direct } \\
\text { effects on psychological characteristics, which in } \\
\text { turn impact employees' performance. } \\
\text { Environmental variables combine their effects on } \\
\text { psychological characteristics that cause an impact } \\
\text { on employees' performance. }\end{array}$ & 3 \\
\hline Sloof & 94 & not specified & $80 \mathrm{~min}$ & $\begin{array}{l}\text { Subjects in the volatile environment are more } \\
\text { strongly influenced by the presence of noise. More } \\
\text { noise not only leads to a stronger stimulus to work, } \\
\text { but also has a demotivating impact. On the one } \\
\text { hand, more noise weakens incentives because the } \\
\text { impact of effort on compensation becomes smaller } \\
\text { relative to the impact of noise; on the other hand, } \\
\text { noise strengthens effort incentives because subjects } \\
\text { are more motivated to attain } \\
\text { a certain (minimum) income target. }\end{array}$ & 3 \\
\hline Smith & $36-34$ & $65 \mathrm{~dB}$ & some hours & $\begin{array}{l}\text { Office noise can disrupt performance on working } \\
\text { memory tasks (i.e., mental arithmetic) but that this } \\
\text { disruption can be habituated to } \\
\text { after a period of time in noise. }\end{array}$ & 2 \\
\hline Tomic & $31 / 11$ & not specified & not specified & $\begin{array}{c}\text { Increasing internal noise released resources that } \\
\text { could be used to store other stimuli more precisely; } \\
\text { increasing external noise } \\
\text { had no such effect on memory. }\end{array}$ & 3 \\
\hline Wright & 54 & $30-78 \mathrm{~dB}$ & $40 \mathrm{~min}$ & $\begin{array}{l}\text { They found significantly slower psychomotor } \\
\text { speed (urban), reduced working memory and } \\
\text { episodic memory (urban and social), and more } \\
\text { cautious decision-making (executive function, } \\
\text { urban) under noise conditions. }\end{array}$ & 2 \\
\hline
\end{tabular}




\section{Discussion}

The aim of this work was to analyze the most recent scientific literature to identify a correlation between exposure to noisy sources and the development of neurobehavioral disorders, particularly in the workplace. All the studies included defined the exposure to noise as related to the occupational setting, both as noise coming from the work procedures and noise coming from the environment in which the workplace is located.

First of all, our results actually highlighted a not very large number of articles; this could indicate a still current difficulty in approaching this complex issue. A significant amount of data in the scientific literature, in fact, concerns the already known effects of noise on the human body, such as those manifested by the cardiovascular system, and even to a lesser extent the insights into neurobehavioral disorders. After that, in our review, several publications and in particular the experimental studies, concerned working sectors in which they must pay a lot of attention and concentration in every procedure they perform, such as for example military personnel or surgical teams. This observation did not surprise us; in fact, tasks that require continuous and careful monitoring of signals (e.g., warning or alarm systems) can in fact be negatively affected by noise and can be used in experimental studies.

The studies available on the effect of noise in the workplace show how this risk can negatively affect the performance of certain activities, acting in particular on the level of performance and safety; for this reason, even accidents and injuries can be a sentinel indicator of a decline in performance $[59,65,66]$, as well as distraction errors [67] or sickness absence among workers [68].

Exposure to noise can be reduced memory capacity [69-71] and short periods of inefficiency/unproductivity [72,73], especially when prolonged visual attention is required $[74,75]$. However, the evidence of the negative effects of noise on productivity in the workplace is still unclear and controversial. For example, a relationship between sound pressure levels and work productivity has not yet been demonstrated and some publications show opposite results, such as Habibi's experiment, where increasing the exposure noise increased (instead of decreasing) the speed of execution of some works [76]. Other studies indicate that absence from work is also associated with several variables to consider, such as gender, age [77], and smoking behavior [78].

Another working sector most examined in our analysis is that concerning the school staff. The noise in school classrooms originates from external sources, such road traffic, and from internal sources such as operators and pupils [79]. In noisy and reverberating classrooms, school-age children experience greater difficulties in both language perception and listening than adults [80-82]. The performance at school of children can be negatively affected by environmental noise, creating interferences in pupils' attention and motivation [83,84], disturbing reading comprehension [85,86], short-term memory [86,87], mathematical skills [88,89], and inducing some kind of hyperactivity [89,90].

These aspects can be decisive in children, as they interfere with language learning processes and phonation: they can favor the onset of dysphonia and dyslexia phenomena due to lack of or reduced control of phonation [91].

Several studies have analyzed the effects of exposure to environmental noise in children, relating to learning, the degree of interest, motivation, and stimulus. For example, research on school-age populations residing near European and international airports showed that they were unable to perform some difficult and complex tasks as well as a control group residing in quiet neighborhoods [92]. There is also some scientific evidence that children exposed to sources of intense noise are more likely to experience impairments in reading and language, especially in the case of pre-existing difficulties. 
Considering all this evidence, the World Health Organization Parma Declaration demanded that all the stakeholders get cooperatively involved in reducing the exposure of children to noise to protect them from its harmful effects [93]. The recommended threshold of WHO guidelines for noise level in school classrooms is $35 \mathrm{~dB}(\mathrm{~A})$ : this level should prevent disturbance of communication during class. Actually, it is very common that these noise limits are exceeded and noise intensity in schools can reach as much as 60-80 dB(A) in normal classes; during school workshops and in sport areas, the limit values for workplace can be exceeded [94].

It is also necessary to consider the complexity of the individual factors, involved in the onset of effects and symptoms; some of these seems to be individual sensitivity to noise or coping strategies. For example, from a study conducted on young women [95], it emerged that noise can cause a physiological reaction to stress when they are not effective or there are no suitable strategies to counteract it (for example, the disturbance caused by noise was less annoying for those who knew they could close the windows).

Even how leadership quality is assessed appears to mitigate the negative effects of occupational noise exposure [96], as exposed employees may feel that the problem is recognized and addressed by management; such reassurance could alleviate stress induced by noisy sources. Moreover, it cannot be excluded that some of these individual variables, such as subjective noise sensitivity, paranoia and sleep quality, can be used as positive predictors for the onset of chronic noise exposure impairments [97].

In recent years, as also found in our analysis, many authors are shifting the focus of their research on the neuro-physiological and biochemical alterations suffered by the nervous system and the auditory system, due to noise. In fact, from the data found also through our analysis, it can be hypothesized that noise can directly cause neurobehavioral alterations (through biochemical mechanisms) or indirectly (as a consequence of hearing loss or speech intelligibility or due to its distracting action). Some studies have shown how, with the same sound pressure level, the annoyance increases the more the high frequency content of the noise increases, because such high values interfere with verbal communications [98]. Furthermore, the increased effort of interpretation required to compensate for this discomfort causes tension and psychological fatigue in the exposed subjects, leading to unconscious behavioral modifications [99].

As for the biochemical hypotheses, some experimental studies have shown that noise exposure can cause structural damage to the cochlea and stimulate hyperactivity in the central auditory system, including the cochlear nucleus, inferior colliculus, and auditory cortex. Furthermore, non-classical hearing-sensitive brain areas can (e.g., the lateral amygdala and striatum) can be triggered by noise exposure, which directly activates the brain's emotion-fear system via the thalamus. In this way, noise can activate defense responses involving the mechanisms of the hypothalamus-pituitaryadrenal (HPA) axis. Long-lasting activation of the HPA axis can cause disturbances in hormonal balance as well as morphological and functional changes in the brain, which may be the potential mechanism for subsequent noise-induced cognitive impairment and neurobehavioral manifestations [100-103]. 
A strong element of this scientific work is that we have not found another systematic review that addresses this issue in the same way as we do. At the same time, another past systematic review would have given us the opportunity, updating the scientific literature, to compare ourselves with past works and highlight the differences or changes made in the approach to these issues. Other limitations of this review could be the wide variability of samples selected in the various studies, the wide diversity of categories examined, and sometimes a non-standardized and validated methodology regarding questionnaires administered to the exposed or scientific experiments. Additionally, some of the studies lack quantitative measurements and description of the characteristics of noise, thus making it difficult identifying the detrimental and annoying features of noise to plan targeted interventions. Eventually, confounding factors related to the possible extraprofessional noise exposure should be addressed. In fact, even though all the studies refer to occupational noise and its effects, we cannot exclude voluptuary noise exposure of the subjects involved in the studies. However, in all studies, the professional exposure results the main source of noise identified by the investigators, thus making it possible to relate it to the neurobehavioral effects described.

\section{Conclusions}

In conclusion, the issue is still widely debated and involves more and more aspects. A greater number of studies will be needed to bring new knowledge on this topic, both as regards the evidence of behavioral disorders and as regards the hormonal and biochemical knowledge underlying these alterations, in order to prevent inconvenience for residents in the areas most exposed and for all those workers who report such disturbances. New opportunities for intervention are desirable in the future, including increased public awareness, worker training programs and education, government intervention addressing health and safety concerns, promotion of regulation, and government funding to enforce higher safety measures, especially in some work sectors such as schools.

Author Contributions: Conceptualization, V.T., N.M. and G.A.; methodology, V.T., N.M. and L.G.L.; software V.R. and L.V.; validation, L.V., R.P.G. and S.D.S.; formal analysis, V.T., V.R. and L.G.L.; investigation, V.T., N.M. and G.A.; resources, S.D.S. and G.A.; data curation, V.T. and L.V.; writing-original draft preparation, V.T., N.M. and L.G.L.; writing-review and editing, V.T., N.M. and R.P.G.; visualization, L.G.L.; supervision, N.M. and G.A.; project administration, N.M. and G.A.; funding acquisition, G.A. All authors have read and agreed to the published version of the manuscript.

Funding: This research was funded by the National Institute for Insurance against Accidents at Work (INAIL)-BRIC 2019-theme ID 14 “Innovative aspects related to the prevention of noise and vibration risk: development of devices based on Active Noise Control and Active Vibration Control technology for worker protection and measures also with a view to preventing the extra-auditory effects of noise" funds granted by Resolution of Central Director of INAIL Department of Research n. 899 of 2019/12/18, modified by subsequent resolutions n. 904 of 2019/12/23 and 2020/01/24.

Institutional Review Board Statement: Not Applicable.

Informed Consent Statement: Not Applicable.

Data Availability Statement: Not Applicable.

Conflicts of Interest: The authors declare no conflict of interest. 


\section{Appendix A}

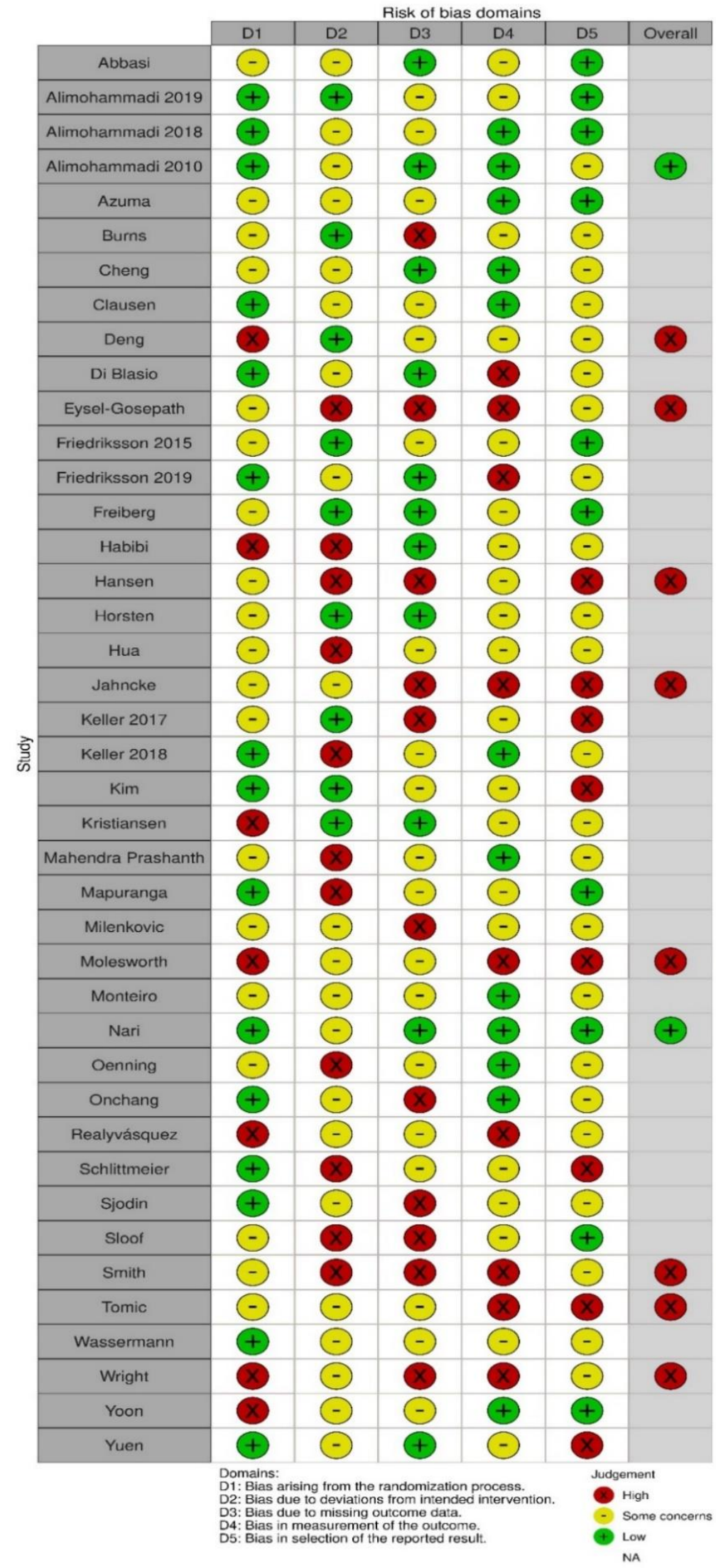

Figure A1. Risk of bias summary. 


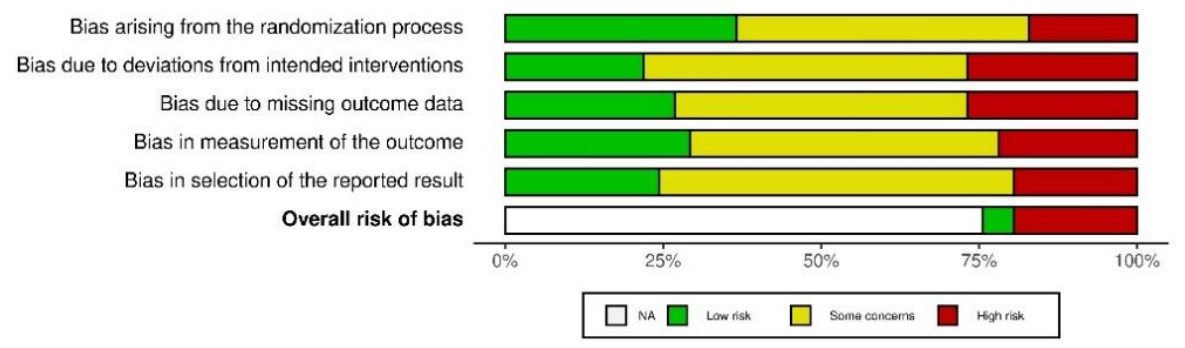

Figure A2. Risk of bias summary.

\section{References}

1. Di Fabio, A. Positive Healthy Organizations: Promoting well-being, meaningfulness, and sustainability in organizations. Front. Psychol. 2017, 8, 1938. [CrossRef]

2. Di Fabio, A. The Psychology of Sustainability and Sustainable Development for Well-Being in Organizations. Front. Psychol. 2017, 8, 1534. [CrossRef] [PubMed]

3. Di Fabio, A.; Rosen, M.A. Opening the Black Box of Psychological Processes in the Science of Sustainable Development: A New Frontier. Eur. J. Sustain. Dev. Res. 2018, 2, 1693. [CrossRef]

4. Evans, G.W.; Hygge, S.; Bullinger, M. Chronic noise and psychological stress. Psychol. Sci. 1995, 6, 333-338. [CrossRef]

5. Cohen, S.; Evans, G.W.; Stokols, D.; Krantz, D.S. Behavior, Health, and Environmental Stress; Plenum: New York, NY, USA, 1986.

6. WHO. Guidelines for Community Noise; Berglund, B., Lindvall, T., Dietrich, S., Eds.; 1999; Available online: https://www.who.int/ docstore/peh/noise/Comnoise-1.pdf (accessed on 31 March 2021).

7. Tomei, G.; Anzani, M.F.; Casale, T.; Tomei, F.; Piccoli, F.; Cerratti, D.; Paolucci, M.; Filippelli, C.; Fioravanti, M. Extra-auditory effects of noise. G. Ital. Med. Lav. Ergon. 2009, 31, 37-48.

8. Carter, N.L.; Hunyor, S.N.; Crawford, G.; Kelly, D.; Smith, A.J.M. Environmental Noise and Sleep-A Study of Arousals, Cardiac Arrhythmia and Urinary Catecholamines. Sleep 1994, 17, 298-307.

9. Babisch, W. The noise/stress concept, risk assessment and research needs. Noise Health 2002, 4, 1-11. [PubMed]

10. Ohrstrom, E.; Skanberg, A. Sleep disturbances from road traffic and ventilation noise laboratory and field experiments. J. Sound Vib. 2004, 271, 279-296. [CrossRef]

11. Lercher, P. Environmental noise: A contextual public health perspective. In Noise and Its Effects; Luxon, L.M., Prasher, D., Eds.; Wiley: Hoboken, NJ, USA, 2007.

12. Chiovenda, P.; Pasqualetti, P.; Zappasodi, F.; Ercolani, M.; Milazzo, D.; Tomei, G.; Capozzella, A.; Tomei, F.; Rossini, P.M.; Tecchio, F. Environmental noise-exposed workers: Event-related potentials, neuropsychological and mood assessment. Int. J. Psychophysiol. 2007, 65, 228-237. [CrossRef]

13. Stansfeld, S.A.; Matheson, M.P. Noise Pollution: Non-Auditory Effects on Health. Br. Med. Bull. 2003, 68, 243-257. [CrossRef] [PubMed]

14. Stansfield, S.A. Noise, noise sensitivity and psychiatric disorder: Epidemiological and psychophysiological studies. Psychol. Med. 1992, 22, 44. [CrossRef]

15. Caerphilly and Speedwell collaborative heart disease studies. The Caerphilly and Speedwell Collaborative Group. J. Epidemiol. Community Health 1984, 38, 259-262. [CrossRef] [PubMed]

16. Thomson, D.J.; Jones, C.J.C.; Wu, T.X.; De France, A. The influence of the non-linear stiffness behaviour of rail pads on the track component of rolling noise. Sage J. 1999, 213. [CrossRef]

17. Öhrström, E.; Björkman, M.; Rylander, R. Noise annoyance with regard to neurophysiological sensitivity, subjective noise sensitivity and personality variables. Psychol. Med. 1988, 18, 605-613. [CrossRef] [PubMed]

18. Guski, R. Personal and social variables as co-determinants of noise annoyance. Noise Health 1999, 1, 45-56. [PubMed]

19. Saha, S.; Gandhi, A.; Das, S.; Kaur, P.; Singh, S.H. Effect of noise stress on some cardiovascular parameters and audiovisual reaction time. Indian J. Physiol. Pharmacol. 1996, 40, 35-40.

20. Gomes, L.M.P.; Martinho Pimenta, A.J.F.; Castelo Branco, N.A.A. Effects of occupational exposure to low frequency noise on cognition. Aviat. Space Environ. Med. 1999, 70, A115-A118.

21. Hygge, S.; Boman, E.; Enmarker, I. The effects of road traffic noise and meaningful irrelevant speech on different memory systems. Scand. J. Psychol. 2003, 44. [CrossRef]

22. Haines, M.M.; Stansfeld, S.A.; Job, R.F.; Berglund, B.; Head, J. Chronic aircraft noise exposure, stress responses, mental health and cognitive performance in school children. Psychol. Med. 2001, 31, 265-277. [CrossRef]

23. Hygge, S. Classroom experiments on the effects of different noise sources and sound levels on long-term recall and recognition in children. Appl. Cogn. Psychol. 2003, 17, 895-914. [CrossRef]

24. Ristovska, G.; Dragan, G.; Pop-Jordanova, N. Psychosocial effects of community noise: Cross sectional study of school children in urban center of Skopje, Macedonia. Croat. Med. J. 2004, 45, 473-476.

25. Mahendra Prashanth, K.V.; Venugopalachar, S. The possible influence of noise frequency components on the health of exposed industrial workers-A review. Noise Health 2011, 13, 16-25. [CrossRef] [PubMed] 
26. European Directives on Safety and Health at Work. Available online: https://osha.europa.eu/it/legislation/directives/82 (accessed on 22 May 2021).

27. Moher, D.; Liberati, A.; Tetzlaff, J.; Altman, D.G.; The PRISMA Group. Prisma Statement. Evidence 2015, 7, e1000114. [CrossRef]

28. Torre, G.L.; Backhaus, I.; Mannocci, A. Rating for narrative reviews: Concept and development of the International Narrative Systematic Assessment tool. Senses Sci. 2015, 2, 31-35. [CrossRef]

29. Wells, G.A.; Shea, B.; O'Connel, D. The Newcastle-Ottawa Scale (NOS) for Assessing the Quality of Non-Randomized Studies in Meta-Analyses. 2009. Available online: http:/ / www.ohrica/programs/clinical_epidemiology/oxford (accessed on 7 May 2020).

30. Shea, B.J.; Grimshaw, J.M.; Wells, G.A.; Boers, M.; Andersson, N.; Hamel, C.; Porter, A.C.; Tugwell, P.; Moher, D.; Bouter, L.M. Development of AMSTAR: A measurement tool to assess the methodological quality of systematic reviews. BMC Med. Res. Methodol. 2007, 7, 10. [CrossRef] [PubMed]

31. Jadad, A.R.; Moore, R.A.; Carroll, D.; Jenkinson, C.; Reynolds, D.J.; Gavaghan, D.J.; Mc Quay, H.J. Assessing the quality of reports of randomized clinical trials: Is blinding necessary? Control. Clin. Trials 1996, 17, 1-12. [CrossRef]

32. McGuinness, L.A.; Higgins, J.P.T. Risk-of-bias VISualization (robvis): An R package and Shiny web app for visualizing risk-of-bias assessments. Res. Synth. Methods 2021, 12, 55-61. [CrossRef]

33. Van Eck, N.J.; Waltman, L. Software survey: VOSviewer, a computer program for bibliometric mapping. Scientometrics 2010, 84, 523-538. [CrossRef] [PubMed]

34. Freiberg, A.; Schefter, C.; Girbig, M.; Murta, V.C.; Seidler, A. Health effects of wind turbines in working environments-A scoping review. Scand. J. Work Environ. Health 2018, 44, 351-369. [CrossRef]

35. Horsten, S.; Reinke, L.; Absalom, A.R.; Tulleken, J.E. Systematic review of the effects of intensive-care-unit noise on sleep of healthy subjects and the critically ill. Br. J. Anaesth. 2018, 120, 443e452. [CrossRef]

36. Yuen, F.K. A vision of the environmental and occupational noise pollution in Malaysia. Noise Health 2014, 16, 427-436. [CrossRef]

37. Alimohammadi, I.; Kanrash, F.A.; Abolghasemi, J.; Vosoughi, S.; Rahmani, K.; Chalak, M.H. Relationship Between Noise Annoyance and Cognitive Performance in Automotive Workers Exposed to Chronic Noise. J. UOEH 2019, 41, 375-385. [CrossRef] [PubMed]

38. Monteiro, R.; Tomé, D.; Neves, P.; Silva, D.; Rodrigues, M.A. The interactive effect of occupational noise on attention and short-term memory: A pilot study. Noise Health 2018, 20, 190-198. [CrossRef] [PubMed]

39. Hua, H.; Emilsson, M.; Ellis, R.; Widén, S.; Möller, C.; Lyxell, B. Cognitive skills and the effect of noise on perceived effort in employees with aided hearing impairment and normal hearing. Noise Health 2014, 16, 79-88. [CrossRef] [PubMed]

40. Cheng, H.; Sun, G.; Li, M.; Yin, M.; Chen, H. Neuron loss and dysfunctionality in hippocampus explain aircraft noise induced working memory impairment: A resting-state fMRI study on military pilots. Biosci. Trends 2019, 13, 430-440. [CrossRef]

41. Wassermann, C.S.; Segool, W. Working in and with Noise: The Impact of Audio Environment on Attention. J. Neurother. Investig. Neuromodulation Neurofeedback Appl. Neurosci. 2013, 17, 203-212. [CrossRef]

42. Keller, M.D.; Ziriax, J.M.; Barns, W.; Sheffield, B.; Brungart, D.; Thomas, T.; Jaeger, B.; Yankaskas, K. Performance in noise: Impact of reduced speech intelligibility on Sailor performance in a Navy command and control environment. Hear Res. 2017, 349, 55-66. [CrossRef]

43. Yoon, J.H.; Won, J.U.; Lee, W.; Jung, P.K.; Roh, J. Occupational noise annoyance linked to depressive symptoms and suicidal ideation: A result from nationwide survey of Korea. PLoS ONE 2014, 9, e105321. [CrossRef]

44. Di Biasio, S.; Shtrepi, L.; Puglisi, G.E.; Astolfi, A. A Cross-Sectional Survey on the Impact of Irrelevant Speech Noise on Annoyance, Mental Health and Well-being, Performance and Occupants' Behavior in Shared and Open-Plan Offices. Int. J. Environ. Res. Public Health 2019, 16, 280. [CrossRef]

45. Fredriksson, S.; Hammar, O.; Torén, K.; Tenenbaum, A.; Persson Waye, K. The effect of occupational noise exposure on tinnitus and sound-induced auditory fatigue among obstetrics personnel: A cross-sectional study. BMJ Open 2015, 5, e005793. [CrossRef]

46. Alihommadi, I.; Nassiri, P.; Azkhosh, M.; Hoseini, M. Factors affecting road traffic noise annoyance among white-collar employees working in Tehran. Iran. J. Environ. Health. Sci. Eng. 2010, 7, 25-34.

47. Azuma, K.; Ikeda, K.; Kagi, N.; Yanagi, U.; Osawa, H. Evaluating prevalence and risk factors of building-related symptoms among office workers: Seasonal characteristics of symptoms and psychosocial and physical environmental factors. Environ. Health Prev. Med. 2017, 22, 38. [CrossRef]

48. Sjodin, F.; Kjellberg, A.; Knutsson, A.; Landström, U.; Lindberg, L. Noise and stress effects on preschool personnel. Noise Health 2012, 14, 166-178. [CrossRef]

49. Oenning, N.S.X.; Klarmann Ziegelmanna, P.; Niegia Garcia de Goularta, B.; Niedhammer, I. Occupational factors associated with major depressive disorder: A Brazilian population-based study. J. Affect. Disord. 2018, 240, 48-56. [CrossRef] [PubMed]

50. Deng, X.F.; Guo-Qi, S.; Li-Li, G.; Chuan-An, Z.; Yong-Jun, C. Analysis on Risk Factors of Depressive Symptoms in Occupational Noise-induced Hearing Loss Patients: A Cross-sectional Study. Noise Health 2019, 21, 17-24.

51. Nari, F.; Un Kyung, K.; Soo Hyun, K.; Eun-Cheol, P.; Sung-In, J. Association between Occupational Noise and Vibration Exposure and Insomnia among Workers in Korea. Life 2020, 10, 46. [CrossRef] [PubMed]

52. Abbasi, M.; Mohammad Reza, M.; Arash, A.; Seyyed, A.Z.; Mohammad Hossein, E. Impact of wind turbine sound on general health, sleep disturbance and annoyance of workers: A pilot- study in Manjil wind farm, Iran. J. Environ. Health Sci. Eng. 2015, 13, 71. [CrossRef] 
53. Alimohammadi, I.; Ahmadi Kanrash, F.; Abolaghasemi, J. Effect of chronic noise exposure on aggressive behavior of automotive industry workers. Int. J. Occup. Environ. Med. 2018, 9, 170-175. [CrossRef]

54. Milenovic, M.; Živković, S.; Veljković, M. Cap 12 Noise and Aggressiveness in the Workplace. In Acoustics and Vibration of Mechanical Structures_AVMS-2017; Herisanu, N., Marinca, V., Eds.; Springer: Berlin/Heidelberg, Germany, 2018 ; Volume 198.

55. Kim, Y.J. Impact of Work Environments and Occupational Hazards on Smoking Intensity in Korean Workers. Workplace Health Saf. 2016, 64, 3. [CrossRef] [PubMed]

56. Burns, K.N.; Sayler, S.K.; Neitzel, R.L. Stress, health, noise exposures, and injuries among electronic waste recycling workers in Ghana. J. Occup. Med. Toxicol. 2019, 14, 1. [CrossRef]

57. Gosepath, K.E.; Daut, T.; Pinger, A.; Lehmacher, W.; Erren, T. Effects of noise in primary schools on health facets in German teachers. Noise Health 2012, 14, 129-134.

58. Fredriksson, S.; Jeong-Lim, K.; Kjell, T.; Lennart, M.; Kim, K.; Söderberg, M.; Persson Waye, K. Working in preschool increases the risk of hearing-related symptoms: A cohort study among Swedish women. Int. Arch. Occup. Environ. Health 2019, 92, 1179-1190. [CrossRef] [PubMed]

59. Kristiansen, J.; Søren, P.L.; Persson, R.; Shibuya, H.; Nielsen, P.M.; Scholz, M. A study of classroom acoustics and school teachers' noise exposure, voice load and speaking time during teaching, and the effects on vocal and mental fatigue development. Int. Arch. Occup. Environ. Health 2014, 87, 851-860. [CrossRef]

60. Onchang, R.; Hawker, D. Community noise exposure and annoyance, activity interference, and academic achievement among university students. Noise Health 2018, 20, 69-76. [CrossRef]

61. Irgens-Hansen, K.; Gundersen, H.; Sunde, E.; Baste, V.; Harris, A.; Bråtveit, M.; Moen, B.E. Noise exposure and cognitive performance: A study on personnel on board Royal Norwegian Navy vessels. Noise Health 2015, 17, 320-327. [CrossRef]

62. Molesworth, B.R.C.; Burgess, M.; Zhou, A. The effects of noise on key workplace skills. J. Acoust. Soc. Am. 2015, 138, 2054. [CrossRef] [PubMed]

63. Jahncke, H.; Staffan, H.; Halin, N.; Green, A.M.; Dimberg, K. Open-plan office noise: Cognitive performance and restoration. J. Environ. Psychol. 2011, 31, 373e382. [CrossRef]

64. Smith, A.; Waters, B.; Jones, H. Effects of prior exposure to office noise and music on aspects of working memory. Noise Health 2010, 12, 235-243. [CrossRef] [PubMed]

65. Mapuranga, M.; Maziriri, E.T.; Letshaba, R.K.; Chitamba, A. Does occupational noise matter amongst manufacturing (small and medium enterprises) workers? Empirical evidence from Magaba, Mbare, Zimbabwe. S. Afr. J. Commun. Disord. 2020, 67, a680. [CrossRef]

66. Sloof, F.; Van Praag, C.M. The effect of noise in a performance measure on work motivation: A real effort laboratory experiment. Labour Econ. 2010, 17, 751-765. [CrossRef]

67. Keller, S.; Franziska, T.; Semmer, K.N.; Holzer, E.; Candinas, D.; Brink, M.; Beldi, G. Noise in the Operating Room Distracts Members of the Surgical Team. An Observational Study. World J. Surg. 2018, 42, 3880-3887. [CrossRef] [PubMed]

68. Clausen, T.; Kristiansen, J.; Vinsløv Hansen, J.; Hyld Pejtersen, J.; Burr, H. Exposure to disturbing noise and risk of long-term sickness absence among office workers: A prospective analysis of register-based outcomes. Int. Arch. Occup. Environ. Health 2013, 86, 729-734. [CrossRef] [PubMed]

69. Hockey, G.R.J. Stress and the cognitive components of skilled performance. In Human Stress and Cognition; Hamilton, V., Warburton, D.M., Eds.; John Wiley: Chichester, UK, 1979.

70. Jones, D.M.; Chapman, A.J. Noise and Society; John Wiley \& Sons: Chichester, UK, 1984.

71. Tomić, I.; Bays, P.M. Internal but not external noise frees working memory resources. PLoS Comput. Biol. 2018, 14, e1006488. [CrossRef]

72. Realyvásquez, A.; Maldonado-Macías, A.A.; García-Alcaraz, J.; Cortés-Robles, G.; Blanco-Fern, J. Structural Model for the Effects of Environmental Elements on the Psychological Characteristics and Performance of the Employees of Manufacturing Systems. Int. J. Environ. Res. Public Health 2016, 13, 104. [CrossRef] [PubMed]

73. Schlittmeier, S.J.; Liebl, A. The Effects of Intelligible Irrelevant Background Speech in Offices-Cognitive Disturbance, Annoyance, and Solutions; Emerald 2014. Available online: www.emeraldinsight.com/0263-2772.htm (accessed on 31 March 2021).

74. Broadbent, D.E.; Broadbent, M.H.P. Recency Effects in Visual Memory. Q. J. Exp. Psychol. 1981, 33, 1-15. [CrossRef]

75. Berglund, B.; Lindvall, T. Community Noise; Archives of the Center for Sensory Research, 2; Stockholm University: Stockholm, Sweden, 1995.

76. Habibi, E.; Habibollah, D.; Dehkordy, S.E.; Maracy, M.R. Evaluation of the effect of noise on the rate of errors and speed of work by the ergonomic test of two-hand co-ordination. Int. J. Prev. Med. 2013, 4, 538-545. [PubMed]

77. Allebeck, P.; Mastekaasa, A. Causes of sickness absence: Research approaches and explanatory models. Scand. J. Public Health 2004. [CrossRef]

78. Christensen, J.S.; Nielsen, O.; Tjønneland, A.; Nordsborg, R.B.; Jensen, S.S.; Thorkild, I.A.; Sørensen, M. Long-term exposure to residential traffic noise and changes in body weight and waist circumference: A cohort study. Environ. Res. 2015, 143, 154-161. [CrossRef]

79. Shield, B.M.; Conetta, R.; Connolly, D.; Cox, T.; Mydlarz, C. A survey of acoustic conditions and noise levels in secondary school classrooms in England. J. Acoust. Soc. Am. 2015, 137, 177-188. [CrossRef]

80. Stansfeld, S.; Clark, C. Health effects of noise exposure in children. Curr. Environ. Health Rep. 2015, 2, 171-178. [CrossRef] 
81. Klatte, M.; Lachmann, T.; Meis, M. Effects of noise and reverberation on speech perception and listening comprehension of children and adults in a classroom-like setting. Noise Health 2010, 12, 270-282. [CrossRef]

82. Valente, D.L.; Plevinsky, H.M.; Franco, J.M.; Heinrichs-Graham, E.C.; Lewis, D.E. Experimental investigation of the effects of the acoustical conditions in a simulated classroom on speech recognition and learning in children. J. Acoust. Soc. Am. 2012, 131, 232-246. [CrossRef] [PubMed]

83. Hygge, S. Noise and cognition in children. In Encyclopedia of Environmental Health; Nriagu, J.O., Ed.; Elsevier: Burlington, VT, USA, 2011; Volume 4, pp. 146-151.

84. Shield, B.; Dockrell, J. The effects of noise on children at school: A review. Build. Acoust. 2003, 10, 97-116. [CrossRef]

85. Clark, C.; Martin, R.; van Kempen, E.; Alfred, T.; Head, J.; Davies, H.W.; Haines, M.M.; Lopez Barrio, I.; Matheson, M.; Stansfeld, S.A. Exposure-effect relations between aircraft and road traffic noise exposure at school and reading comprehension: The RANCH project. Am. J. Epidemiol. 2006, 163, 27-37. [CrossRef]

86. Stansfeld, S.A.; Berglund, B.; Clark, C.; Lopez-Barrio, I.; Fischer, P.; Ohrström, E.; Haines, M.M.; Head, J.; Hygge, S.; van Kamp, I.; et al. Aircraft and road traffic noise and children's cognition and health: A cross-national study. Lancet 2005, 365, 1942-1949. [CrossRef]

87. Clark, C.; Crombie, R.; Head, J.; van Kamp, I.; van Kempen, E.; Stansfeld, S.A. Does traffic-related air pollution explain associations of aircraft and road traffic noise exposure on children's health and cognition? A secondary analysis of the United Kingdom sample from the RANCH project. Am. J. Epidemiol. 2012, 176, 327-337. [CrossRef] [PubMed]

88. Hygge, S.; Evans, G.W.; Bullinger, M. A prospective study of some effects of aircraft noise on cognitive performance in schoolchildren. Psychol. Sci. 2002, 13, 469-474. [CrossRef]

89. Papanikolaou, M.; Skenteris, N.; Piperakis, S.M. Effect of external classroom noise on schoolchildren's reading and mathematics performance: Correlation of noise levels and gender. Int. J. Adolesc. Med. Health 2015, 27, 25-29. [CrossRef]

90. Pujol, S.; Levain, J.P.; Houot, H.; Petit, R.; Berthillier, M.; Defrance, J.; Lardies, J.; Masselot, C.; Mauny, F. Association between ambient noise exposure and school performance of children living in an urban area: A cross-sectional population-based study. J. Urban Health 2014, 91, 256-271. [CrossRef]

91. D’Alessandro, D.; Rini, F.; Vasapollo, R.; Chiarello, G.; Fara, G.M. Le Esperienze Raccolte ed i Programmi di Valutazione del Superamento della Normale Tollerabilità Dell'immissione di Rumore e Vibrazioni. 2004. Available online: http:/ /inquinamentoacustico.it (accessed on 31 March 2021).

92. Cohen, S.; Evans, G.W.; Krantz, D.S.; Stokols, D. Physiological, motivational and cognitive effects of aircraft noise on children. Am. Psychol. 1980, 35, 231-243. [CrossRef]

93. World Health Organization. Protecting Children's Health in a Changing Environment. In Proceedings of the Fifth Ministerial Conference on Environment and Health, Parma, Italy, 10-12 March 2010.

94. Noise in Figures. 2006. Available online: https:/ / osha.europa.eu/en/publications/report-noise-figures (accessed on 20 March 2021).

95. Babisch, W.; Fromme, H.; Beyer, A.; Ising, H. Increased catecholamine levels in urine in subjects exposed to road traffic noise. The role of stress hormones in noise research. Environ. Int. 2001, 26, 475-481. [CrossRef]

96. Hobfoll, S.E. Social and Psychological Resources and Adaptation. Rev. Gen. Psychol. 2002, 6, 307-324. [CrossRef]

97. Wright, B.A.L.; Peters, E.R.; Ettinger, U.; Kuipers, E.; Kumari, V. Moderators of noise-induced cognitive change in healthy adults. Noise Health 2016, 18, 117-132. [CrossRef]

98. Ishiyama, T.; Hashimoto, T. The impact of sound quality on annoyance caused by road traffic noise: An influence of frequency spectra on annoyance. JSAE Rev. 2000, 225, 2230. [CrossRef]

99. Berglund, B.; Lindvall, T.; Schwela, D.H. Guidelines for Community Noise; WHO: Geneva, Switzerland, 1998.

100. Gröschel, M.; Ryll, J.; Götze, R.; Ernst, A.; Basta, D. Acute and long-term effects of noise exposure on the neuronal spontaneous activity in cochlear nucleus and inferior colliculus brain slices. BioMed Res. Int. 2014, 2014, 909260. [CrossRef] [PubMed]

101. Manzoor, N.F.; Licari, F.G.; Klapchar, M.; Elkin, R.L.; Gao, Y.; Chen, G.; Kaltenbach, J.A. Noise-induced hyperactivity in the inferior colliculus: Its relationship with hyperactivity in the dorsal cochlear nucleus. J. Neurophysiol. 2012, 108, 976-988. [CrossRef] [PubMed]

102. Manzoor, N.F.; Gao, Y.; Licari, F.; Kaltenbach, J.A. Comparison and contrast of noise-induced hyperactivity in the dorsal cochlear nucleus and inferior colliculus. Hear Res. 2013, 295, 114-123. [CrossRef] [PubMed]

103. Van Bodegom, M.; Homberg, J.R.; Marloes, J.A.G. Henckens. Modulation of the Hypothalamic-Pituitary-Adrenal Axis by Early Life Stress Exposure. Front. Cell. Neurosci. 2017, 11, 87. [CrossRef] 